\title{
CFD Simulation of $\mathrm{He} / \mathrm{CH}_{4}$ Separation by Hyflon AD60X Membrane
}

\author{
Y. Amini, ${ }^{\text {a, }}$ A. Ghaednian-Jahromi, ${ }^{b}$ J. Karimi-Sabet, ${ }^{a}$ \\ A. Dastbaz, ${ }^{c}$ and A. Hassanvand ${ }^{\mathrm{d}}$ \\ ${ }^{a}$ Nuclear Fuel Cycle Research School, Nuclear Science \\ and Technology Research Institute, Tehran, Iran \\ ${ }^{b}$ Department of Chemical Engineering, Sahand University \\ of Technology, Tabriz, Iran \\ 'School of Chemical Engineering, Faculty of Engineering, \\ University of Tehran, Tehran, Iran \\ dDepartment of Polymer Engineering, Faculty of Engineering, \\ Lorestan University, Khorramabad, Iran

In this research, the membrane separation process was used to separate helium from methane gas. In order to do this, computational fluid dynamics (CFD) was used, and the effect of process parameters on the performance of the membrane separation process was studied by this method. To simulate the hydrodynamics of flow in the channel, the Navier-Stokes equation was used, and the Maxwell-Stefan equation was applied to simulate the mass transfer phenomenon. In addition, Fick's law was utilized to simulate mass transfer in the membrane domain. The impacts of significant parameters such as feed pressure, feed flow rate, and feed concentration on parameters such as $\mathrm{He} / \mathrm{CH}_{4}$ separation factor, methane and helium membrane flux and helium mole fraction in permeate stream were studied. The results of the simulation indicated that the feed pressure of $10 \mathrm{bar}$, feed flow rate of $120 \mathrm{~cm}^{3} \mathrm{~min}^{-1}$, and feed mole fraction of 0.0254 had the best membrane performance in $\mathrm{He} / \mathrm{CH}_{4}$ separation.

Keywords:

helium, methane, membrane separation, CFD simulation, Hyflon AD60X

\section{Introduction}

The importance and applications of helium have increased due to its physical and chemical characteristics. Helium is a non-flammable and inert gas with a small molecular size, and its boiling temperature is low. These unique characteristics increase its applications in industrial, medical, and scientific applications as a cryogenic fluid, protective fluid media, and an inert gas ${ }^{1}$. Currently, $29 \%$ of the global helium supply is consumed by cryogenics and superconductivity users ${ }^{2}$. Among various applications, $20 \%$ of helium supply is used for MRI (Magnetic Resonance Imaging) scanners ${ }^{3}$. In the future, a large amount of helium will be required for nuclear fusion power plants ${ }^{4}$. Market modeling forecasts that helium demand in technological uses may double by $2030^{5,6}$. Therefore, helium production has great importance in the industries.

Natural gas fields are the primary sources for helium extraction, and cryogenic distillation and

"Corresponding author: E-mail: Y_amini@alum.sharif.edu,

Yamini@aeoi.org.ir pressure swing adsorption (PSA) are the main conventional processes in helium recovery and purification $^{7,8}$. Membrane gas separation is another process that can recover and purify helium from natural gas in some stages. Membrane gas separation has specific advantages over conventional separation processes $^{9-15}$. Low environmental impact, low-energy consumption, and ease of operation are the main advantages of this process ${ }^{16}$. To gain an efficient membrane process, membrane material and operating conditions are the critical factors that should be considered ${ }^{17}$. Hyflon AD60X is a perfluoro polymer that has a high chemical, thermal, aging, and solvent resistance ${ }^{18}$. On the other hand, due to high helium permeability (up to 476 barrels) and high $\mathrm{He} / \mathrm{CH}_{4}$ selectivity (up to 169), Hyflon AD60X is an excellent membrane material in $\mathrm{He} / \mathrm{CH}_{4}$ separation $^{19}$.

A detailed study of the fluid dynamic behavior becomes essential for both predicting the process performance and selecting more effective operating conditions $\mathrm{s}^{20-25}$. Recently, computational fluid dynamics (CFD) has become a practical tool for the investigation of fluid flows within different geome- 
tries $^{26-33}$. It is stipulated that CFD has decreased the cost and the required number of experiments for the design and optimization of various processes ${ }^{34-36}$. Therefore, in the following text, the application of the CFD technique for the investigation of $\mathrm{He} / \mathrm{CH}_{4}$ membrane separation will be presented.

Previous researchers and scholars have modestly focused on the membrane separation process in $\mathrm{He} / \mathrm{CH}_{4}$ separation. Laguntsov et al. ${ }^{37}$ considered the membrane as a one-dimensional process, and they also assumed the membrane as a wall without volume to examine the membrane process for separation of helium from natural gas. In their model, the flux of each component of the membrane is related to the permeability and partial pressure difference of that gas on both sides of the membrane. The gas-phase resistance is ignored on both sides of the membrane. In other words, they assumed that the ideal plug flow is running on both sides of the membrane; thus, the concentration of each component is equal in every cross-section of the channels. By their method, several types of one- and twostage membrane separation processes were studied. They showed that the optimal process was a twostage membrane separation with recirculation lines.

Perrin and Stern ${ }^{38}$ studied membrane separation of the $\mathrm{He} / \mathrm{CH}_{4}$ mixture experimentally and theoretically. They simulated $\mathrm{He} / \mathrm{CH}_{4}$ separation by using two types of membrane, including silicon rubber (which is more permeable to methane) and cellulose triacetate (which is more permeable to helium). To simulate the membrane process, they considered the system as a one-dimensional geometry and presumed that structures of membranes are symmetric. Therefore, in real situations, the structure of cellulose triacetate is asymmetric. In addition, they supposed that the permeability is not related to the gas pressure, and axial pressure loss was ignored on both sides of the membrane. The numerical analysis done by these assumptions and the comparison of numerical results with experimental results showed that the agreement improved in the lower stage cuts.

Ahsan and Hussain simulated the separation of helium from fuel gas in the hollow fiber membranes $^{39}$. They considered the one-dimensional geometry and used the approximation of logarithmic mean partial pressure difference on both sides of the membrane as a driving force to penetrate the gases through the membrane. Besides, they considered plug flow at permeate and feed side, and minor pressure losses at the feed side. By these assumptions, they developed a fast and straightforward model to recover helium from a multicomponent gas mixture off course for hollow fiber membranes. Comparison of the literature data and numerical results showed that the model results could be used for the prediction of separation and recovery of helium.

Recently, Naumkin applied CFD simulation to study the separation of helium from methane by various types of flat polymeric membranes in two-dimensional geometry ${ }^{40}$. To simulate the membrane process, the membrane was considered as a wall without volume. Also, the membrane flux of each component was considered dependent on the permeability of every component. The results showed that high membrane selectivity could not always lead to a high degree of mixture separation.

To simulate the membrane separation of helium from methane by the flat inorganic membrane, Volchkov et al. ${ }^{41}$ used the mentioned simulation method. In this study, temperature-related permeability was considered since the used membrane is an inorganic membrane. Thus, the possibility of evaluating the membrane performance at high temperatures (even up to $750 \mathrm{~K}$ ) was accessible.

Although a few researchers have used numerical studies to investigate the flow feature and mass transfer efficiency in the helium membrane separation, there is a lack of a comprehensive numerical study on this process. This study focuses on improving the simulation method with computational fluid dynamics. Therefore, a two-dimensional simulation of $\mathrm{He} / \mathrm{CH}_{4}$ separation by a high-quality membrane material (Hyflon AD60X) were studied. Additionally, both membrane medium and flow channel (upon membrane) were considered in the simulation. In these conditions, the effects of operating parameters (such as feed flow rate, concentration, and pressure) on $\mathrm{He} / \mathrm{CH}_{4}$ separation were investigated.

\section{Numerical simulation}

\section{Computational domains}

In this study, a radial flow pattern occurred on the flat disk membrane surface. Therefore, the 2D axisymmetric model of the membrane system was chosen for the simulations. The membrane system contained a flow channel and membrane domains. The flow channel domain was divided into three subregions: central inlet tube, outlet ring, and membrane channel. Fig. 1 illustrates the full detail of the membrane system, and the governing equations of each domain were determined.

\section{Governing equations for flow channel domain}

In this study, the Navier-Stocks equations were coupled with a mass transfer equation to simulate two-dimensional fluid flow inside the flow channel. The fluid was assumed laminar, Newtonian, and in- 


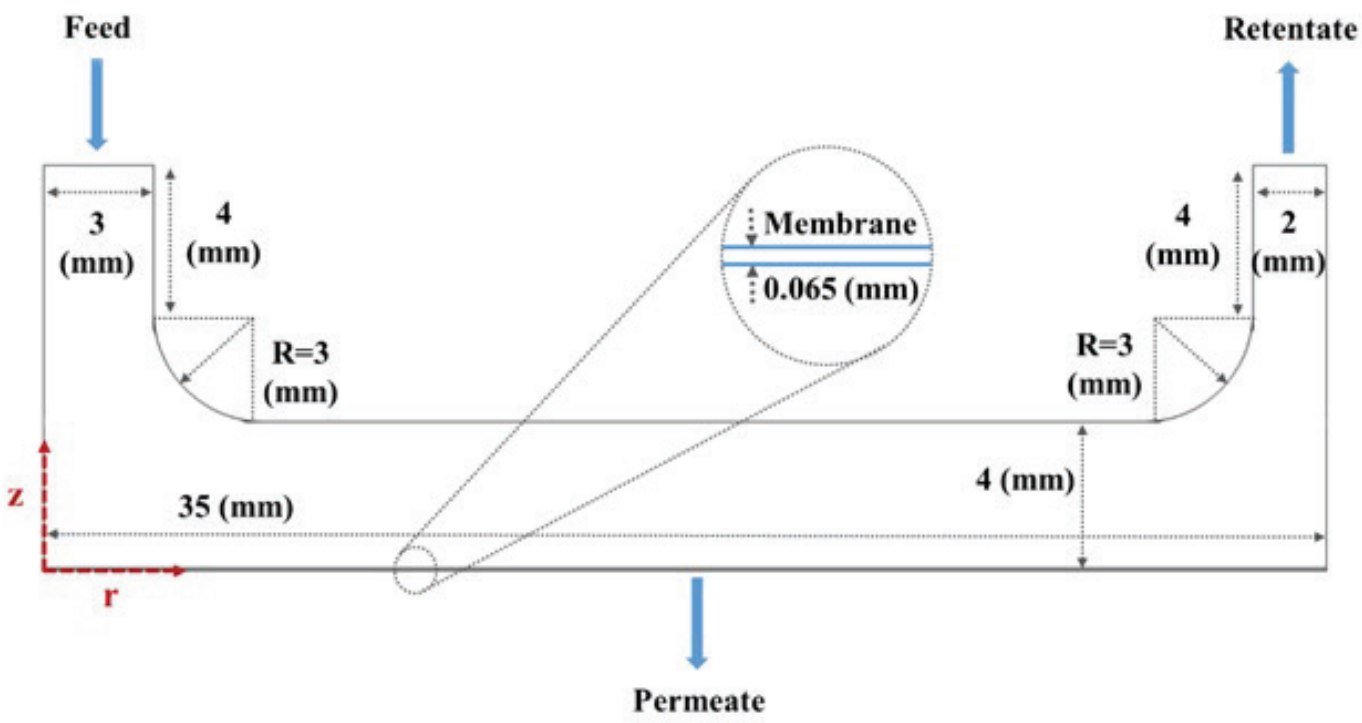

Fig. 1 - Membrane system geometry

compressible. The conservation equations for mass and momentum describing the flow features are given as follows ${ }^{42-51}$ :

$$
\begin{gathered}
\rho \nabla u=0 \\
(\rho u) \nabla u=\nabla \cdot\left(-p I+\mu\left(\nabla u+(\nabla u)^{T}\right)\right)
\end{gathered}
$$

where $\rho, u, \mu$ and $p$ are fluid density, velocity, dynamic viscosity, and fluid pressure, respectively.

As the molecular diffusion in bulk might affect the model results, the interactions among the gases were considered, and the approximation of the dilute solution was abandoned ${ }^{52-54}$. Thus, the Maxwell-Stefan diffusion equation was used in multicomponent species transport. The mass conservation equation for component $\mathrm{i}$ can be written:

$$
\begin{gathered}
\nabla \cdot j_{i}+\rho(u . \nabla) \omega_{i}=R_{i} \\
N_{i}=j_{i}+\rho u \omega_{i}
\end{gathered}
$$

where

$$
\begin{gathered}
j_{i}=-\left(\rho \omega_{i} \sum_{k=1}^{n} D_{i k} d_{k}\right) \\
d_{k}=\nabla x_{k}+\left(x_{k}-\omega_{k}\right) \frac{\nabla p_{A}}{p_{A}} \\
x_{k}=\frac{\omega_{k}}{M_{k}} M_{t} \\
M_{t}=\left(\sum_{i} \frac{\omega_{i}}{M_{i}}\right)^{-1}
\end{gathered}
$$

where $j_{i}, \omega_{i}, D_{i k}, d_{k}$ and $p_{A}$ are mass flux, mass fraction, Maxwell-Stefan diffusion coefficient, driving force, and absolute pressure, respectively. $M_{i}$ and $M_{t}$ are molecular weight for species $i$ and mixture molecular weight.

\section{Governing equation for membrane domain}

Gas permeation in non-porous, dense polymeric membranes is defined by solution-diffusion theory. According to the theory, gas transport occurs by sorption of gas into one surface of the membrane (high-pressure side), then molecular diffusion occurs in the polymer matrix (that is the rate-limiting $\left.\mathrm{step}^{55}\right)$. Desorption of the gas from the other surface of the membrane (low-pressure side) occurs ${ }^{56}$. Based on the solution-diffusion model, the pressure within the thickness of the membrane is uniform. In this regard, as a fixed parameter, the pressure difference above and below the membrane was adjusted at 10 bar. So, the chemical potential gradient of the species across the membrane is represented only as a concentration gradient. Fick's law of diffusion interprets the fundamental mathematical framework for mass transfer across the nonporous membranes or diffusion of species through the membrane, and it was derived by analogy with Fourier's law of heat conduction $^{57-59}$. The species mass conservation for membrane phase and Fick's law are presented as follows:

$$
\begin{gathered}
\nabla \cdot\left(-D_{i} \nabla c_{i}\right)=0 \\
N_{i}^{*}=-D_{i} \nabla c_{i}
\end{gathered}
$$

where $N_{i}^{*}$ and $c_{i}$ are the molar flux and concentration of component $i$.

\section{Boundary conditions}

Boundary conditions for the momentum and mass transfer model in flow channel domain are given as: 
$0(\mathrm{~mm})<r<3(\mathrm{~mm})$ and $z=11.065(\mathrm{~mm})$

$$
\begin{gathered}
-\int_{\partial \Omega} \frac{\rho}{\rho_{s t}}(u . n) \mathrm{d} s=Q_{s v}, \text { (mass flow) } \\
\omega_{i}=\omega_{0, i}, \text { (mass fraction) }
\end{gathered}
$$

where $\rho_{s t}$ and $Q_{s t}$ are the density and volumetric flow rate at standard conditions $\left(0{ }^{\circ} \mathrm{C}\right.$ and $\left.1 \mathrm{~atm}\right)$.

$$
\begin{gathered}
33(\mathrm{~mm})<r<35(\mathrm{~mm}) \text { and } z=11.065(\mathrm{~mm}) \\
p=p_{0} \text {, (pressure) } \\
\left(\mu\left(\nabla u+(\nabla u)^{T}\right)\right) \cdot n=0, \text { (no viscous stress) } \\
\left(-\rho \omega_{i} \sum_{k} D_{i k} d_{k}\right) \cdot n=0 \text {, (outflow) }
\end{gathered}
$$

$r=0(\mathrm{~mm})$ and $0.065(\mathrm{~mm})<z<11.065(\mathrm{~mm})$

$$
\begin{gathered}
u . n=0, \text { (insulation/symmetry) } \\
\left(-p I+\mu\left(\nabla u+(\nabla u)^{T}\right) n=0,\right. \\
\text { (insulation/symmetry) }
\end{gathered}
$$$$
N_{i} \cdot n=0,(\text { axial symmetry) }
$$

$0(\mathrm{~mm})<r<35(\mathrm{~mm})$ and $z=0.065(\mathrm{~mm})$

$$
u=0, \text { (no slip condition) }
$$

$$
N_{i} \cdot n=A\left(K_{i} x_{i} p\left(\frac{M_{i} p_{s t}}{R T_{s t}}\right)-c_{i} M_{i}\right),
$$

(Stiff-Spring continuous flux)

$$
K_{i}=K_{D i}+\frac{F_{i} C_{H i}^{*} b_{i}}{1+b_{i} x_{i} p}
$$

To explain the Stiff-Spring boundary condition, more details about this boundary condition will be presented in the next section.

In addition, at the other boundaries related to flow channel domain:

$$
\begin{gathered}
u=0, \text { (no-slip condition) } \\
-N_{i} \cdot n=0, \text { (no flux) }
\end{gathered}
$$

Due to discontinuities of concentration profile at the boundary between flow channel domain and membrane domain, instead of Dirichlet concentration boundary conditions, the Stiff-Spring boundary condition was used to achieve continuous flux over the boundary ${ }^{60}$. The Stiff-Spring equation was defined as follows:

$$
N_{i} \cdot n=A\left(K_{i} c_{i}^{I}-c_{i}^{I I}\right)
$$

where $i, I$, and $I I$ represent the species, flow channel, and membrane domain, respectively. $A$ is the
Stiff-Spring velocity which should be sufficiently large to allow the term in parentheses to approach zero, $c$ is the molar concentration, and $K$ denotes the partition coefficient ${ }^{60}$. The partition coefficient is defined by the solubility coefficient of species in the membrane. According to the experimental data, Henry's law sorption could apply for the solubility coefficient of helium in Hyflon AD60X ${ }^{61}$, and dual-mode sorption is recommended for calculating the solubility coefficient of methane ${ }^{62}$. Thus, the required parameters for defining partition coefficient are presented in Table 1.

Table 1 -Parameters required for defining the partition coefficient of helium and methane in Hyflon AD60X

\begin{tabular}{c|c|c|c|c}
\hline $\begin{array}{c}\text { Gas } \\
\text { type }\end{array}$ & $\begin{array}{c}K_{D i} \\
\mathrm{~cm}^{3}(\mathrm{STP}) \\
\mathrm{cm}^{-3}[\text { polymer }] \mathrm{atm}^{-1}\end{array}$ & $\begin{array}{c}C_{H i}^{*} \\
\mathrm{~cm}^{3}[\mathrm{STP}] \\
\mathrm{cm}^{-3}[\text { polymer }]\end{array}$ & $\begin{array}{c}b_{i} \\
\mathrm{~atm}^{-1}\end{array}$ & Reference \\
\hline $\mathrm{He}$ & 0.08 & - & - & 32 \\
$\mathrm{CH}_{4}$ & 0.31 & 2.95 & 0.08 & ${ }^{33}$ \\
\hline
\end{tabular}

Boundary conditions for membrane domain are given as:

$$
\begin{gathered}
0(\mathrm{~mm})<r<35(\mathrm{~mm}) \text { and } z=0(\mathrm{~mm}), \\
\quad(\text { concentration) } \\
c_{i}=0, \text { (concentration) }
\end{gathered}
$$

$r=0(\mathrm{~mm})$ and $0(\mathrm{~mm})<z<0.065(\mathrm{~mm})$

$$
N_{i}^{*} \cdot n=0, \text { (axial symmetry) }
$$

$0(\mathrm{~mm})<r<35(\mathrm{~mm})$ and $z=0.065(\mathrm{~mm})$

$$
N_{i}^{*} \cdot n=-A\left(K_{i} x_{i} p\left(\frac{p_{s t}}{R T_{s t}}\right)-c_{i}\right),
$$

(Stiff-Spring continuous flux)

$$
\begin{gathered}
r=35(\mathrm{~mm}) \text { and } 0(\mathrm{~mm})<z<0.065(\mathrm{~mm}) \\
N_{i}^{*} . n=0, \text { (no flux) }
\end{gathered}
$$

\section{Physical properties and transport coefficients}

Helium and methane with the dipole of 0.0 thereby ${ }^{63}$ can be assumed as nonpolar molecules. For nonpolar molecules, the most reliable molecular model is based upon the Lennard-Jones potential energy function. This model is a more realistic molecular model rather than the rigid-sphere approach. Based on this theory, the viscosity expression for a pure gas is expressed as follows:

$$
\mu=2.6693 \frac{\sqrt{M T}}{\sigma^{2} \Omega_{\mu}} 10^{-6}
$$




$$
\begin{gathered}
\Omega_{\mu}=A\left(T^{*}\right)^{-B}+C\left(\exp \left(-D T^{*}\right)\right)+E\left(\exp \left(-F T^{*}\right)\right) \\
T^{*}=\frac{k T}{\varepsilon}
\end{gathered}
$$

where $T$ is temperature, $\Omega_{\mu}$ is the collision integral, $\sigma$ is the collision diameter, $T^{*}$ is the dimensionless temperature, $k$ is the Boltzmann constant, and $\varepsilon$ is the characteristic energy of interaction between molecules. The values of constants $A, B, C, D, E$ and $F$ are given in Table 2 , and $M, \frac{\varepsilon}{k}$ and $\sigma$ are
given in Table 3:

Table 2 -Parameters required for calculating collision integral $^{63}$

\begin{tabular}{c|c|c|c|c|c}
\hline$A$ & $B$ & $C$ & $D$ & $E$ & $F$ \\
\hline 1.16145 & 0.14874 & 0.52487 & 0.77320 & 2.16178 & 2.43787 \\
\hline
\end{tabular}

Table 3 -Parameters required for calculating viscosity

\begin{tabular}{c|c|c}
\hline Parameter & $\mathrm{He}$ & $\mathrm{CH}_{4}$ \\
\hline$M\left(\mathrm{~g} \mathrm{~mol}^{-1}\right)$ & 4 & 16 \\
$\varepsilon / k(\mathrm{~K})$ & 10.22 & 136.5 \\
$\sigma(\AA)$ & 2.576 & 3.822 \\
\hline
\end{tabular}

To calculate the viscosity of the multicomponent gas mixture, an empirical formula proposed by Wilke was used:

$$
\begin{gathered}
\mu_{m i x}=\sum_{i=1}^{n} \frac{x_{i} \mu_{i}}{\sum_{j=1}^{n} x_{j} \phi_{i j}} \\
\phi_{i j}=\frac{1}{\sqrt{8}}\left(1+\frac{M_{i}}{M_{j}}\right)^{-0.5}\left(1+\left(\frac{\mu_{i}}{\mu_{j}}\right)^{0.5}\left(\frac{M_{j}}{M_{i}}\right)^{0.25}\right)^{2}
\end{gathered}
$$

For gas pairs of nonreactive and nonpolar molecules, modern versions of the kinetic theory have been applied to compute forces of repulsion and attraction between the gas molecules. To evaluate the influence of the molecular forces, the LennardJones potential, was used and an equation for the diffusion coefficient presented by HirschfelderBird-Spotz. Their formula for calculation of diffusion coefficient is ${ }^{64,65}$ :

$$
\begin{gathered}
D_{i j}=\frac{0.001858 T^{1.5}\left(\frac{1}{M_{i}}+\frac{1}{M_{j}}\right)^{0.5}}{p \sigma_{i j}^{2} \Omega_{D}} \\
\sigma_{i j}=\frac{\sigma_{i}+\sigma_{j}}{2} \\
\Omega_{D}=A\left(T^{*}\right)^{-B}+C\left(\exp \left(-D T^{*}\right)\right)+ \\
+E\left(\exp \left(-F T^{*}\right)\right)+G\left(\exp \left(-H T^{*}\right)\right)
\end{gathered}
$$

$$
\begin{gathered}
T^{*}=\frac{k T}{\varepsilon_{i j}} \\
\varepsilon_{i j}=\sqrt{\varepsilon_{i} \varepsilon_{j}}
\end{gathered}
$$

where $D_{i j}$ is the diffusivity of i component through $j$ component, $p$ is the absolute pressure, $\sigma_{i j}$ is the collision diameter, $\Omega_{D}$ is the collision integral for molecular diffusion, and $\varepsilon_{i j}$ is a Lennard-Jones parameter which is the energy of molecular interaction for the binary system of $i$ and $j$ in ${ }^{35}$. The values of constants A, $B, C, D, E, F, G$ and $H$ are given in Table 4.

Table 4 -Parameters required for calculating collision integral for molecular diffusion ${ }^{63}$

\begin{tabular}{c|c|c|c|c|c|c|c}
\hline$A$ & $B$ & $C$ & $D$ & $E$ & $F$ & $G$ & $H$ \\
\hline
\end{tabular}

The fluid density is another significant parameter, which should be determined to solve the fluid flow equation. In this study, the fluid includes a mixture of methane and helium gases, which are non-polar and spherical. Therefore, in this research, the ideal gas law (Eq. 39) was used to calculate the mixture density of the two gases.

$$
\rho_{\text {mix }}=\frac{p \sum_{i=1}^{n} M_{i} x_{i}}{R T}
$$

The last remaining parameters are the gases diffusion coefficient in membrane material (Hyflon AD60X). Their values were $1.700 \cdot 10^{-7}$ and $3.762 \cdot 10^{-5} \mathrm{~cm}^{2} \mathrm{~s}^{-1}$ for the methane and helium gases, respectively.

\section{Numerical solution}

\section{Mesh independence and operating conditions}

To obtain numerical solutions, a two-dimensional model with an adequate number of elements was generated. To investigate the mesh quality, the results of average He normal flux in retentate stream (output flow) of the five different computational grids (1989, 4242, 5348, 11386, 20080 elements) were compared. For this purpose, the finite element method of the COMSOL software package was used to obtain numerical solutions. The details of numerical solver can be expressed as:

- Solver: Direct (PARDISO).

- Relative tolerance: 0.00001 .

- Initial damping factor: 0.01 .

- Minimum damping factor: 0.000001 .

- Restriction for step-size update: 10 .

- Recovery damping factor: 0.75 (Automatic). 
Table 5 presents the operating and boundary conditions.

Table 5 -Conditions used for grid study

\begin{tabular}{lcc}
\hline \multicolumn{1}{c|}{ Parameter } & Dimension & Value \\
\hline Feed flow rate $@ \operatorname{STP}\left(Q_{s v}\right)$ & $\left(\mathrm{cm}^{3} \mathrm{~min}^{-1}\right)$ & 60 \\
Retentate pressure $\left(p_{0}\right)$ & $(\mathrm{bar})$ & 10 \\
Temperature $(T)$ & $(\mathrm{K})$ & 308.15 \\
Helium mass fraction in feed $\left(w_{0, \mathrm{He}}\right)$ & $(-)$ & 0.02 \\
Methane mass fraction in the feed $\left(w_{0, \mathrm{CH}_{4}}\right)$ & $(-)$ & 0.98 \\
\hline
\end{tabular}

The results of the grid study were extracted from the software. Fig. 2 compares the normal total flux of different grids. The variation of the average He normal flux showed that the relative error was approximately $0.4 \%$ for grids with 11386 and 20080 elements. Therefore, the geometry with

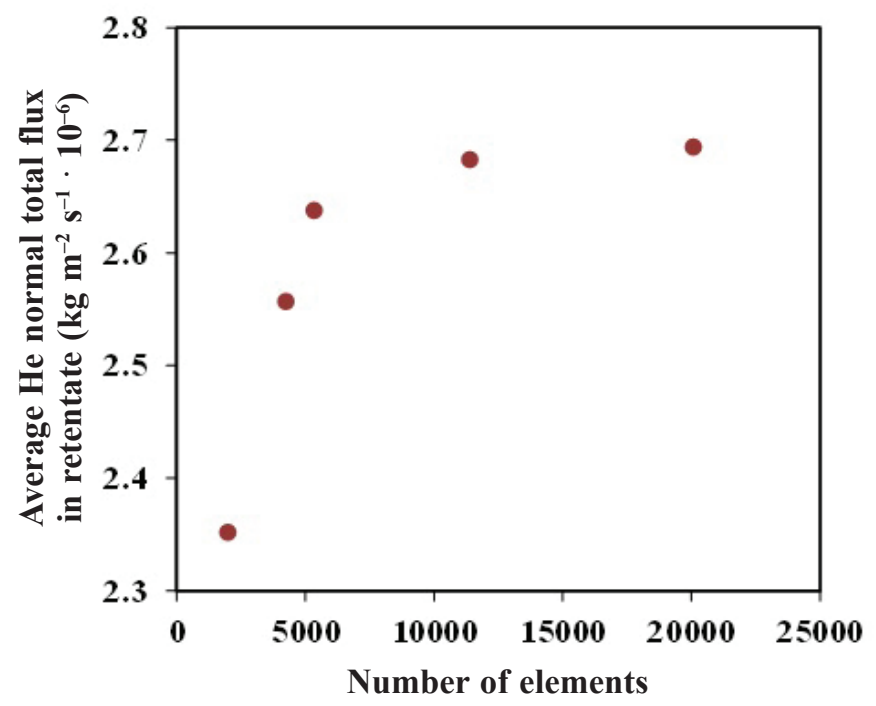

Fig. 2 - Average He normal total flux in retentate stream vs the number of elements
11386 elements was selected as the threshold of the computational domain to apply for further numerical simulations. The generated mesh is presented in Fig. 3.

\section{Method validation}

The simulation results for the permeation of $\mathrm{He}$ and $\mathrm{CH}_{4}$ using the Hyflon AD60X membrane were compared with the experimental data in order to validate the mass transfer $2 \mathrm{D}$ model proposed. As the experimental permeability data of $\mathrm{He}^{66}$ and $\mathrm{CH}_{4}{ }^{62}$ pure gases were available, it was necessary to determine the membrane mass flux of $\mathrm{He}$ and $\mathrm{CH}_{4}$ pure gases from software, and then calculate permeability data according to the permeability definition. As shown in Fig. 4, a good agreement was achieved between our simulation results and experimental data. The result agreed well with the trends observed in the experimental data. This is confirmation that in modelling, consideration of all the transport mechanisms through the membrane system (i.e. mass and momentum transport phenomena in flow channel domain and mass transport phenomena in membrane domain) should be preferred to simpler approaches. Therefore, it may be concluded that this simulation method could be applied for further investigations.

\section{Results and discussion}

\section{Effect of pressure and feed flow rate on $\mathrm{He} / \mathrm{CH}_{4}$ separation factor}

The separation factor is an important parameter that shows the performance of the membrane separation process. According to Eq. 40, which was used for calculating separation factor $\left(\alpha_{\mathrm{He} / \mathrm{CH}_{4}}\right)$, it was necessary to specify the amount of average

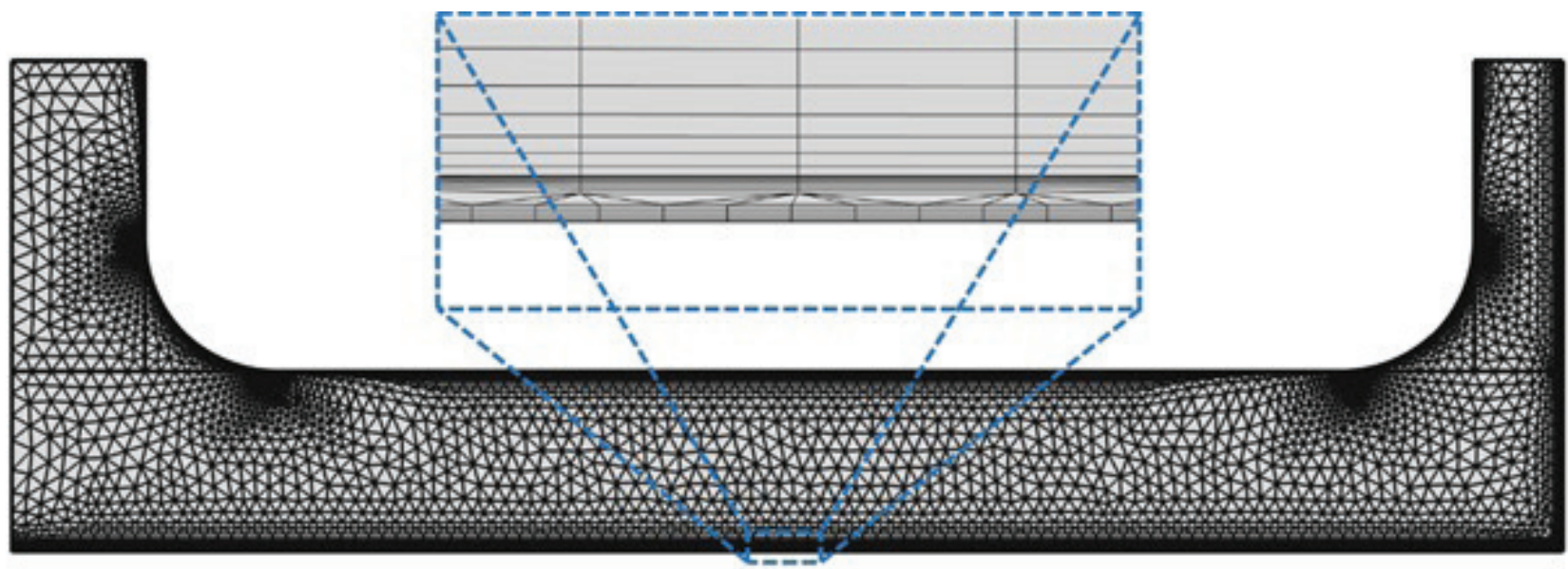

Fig. 3 -Mesh used in membrane simulation 


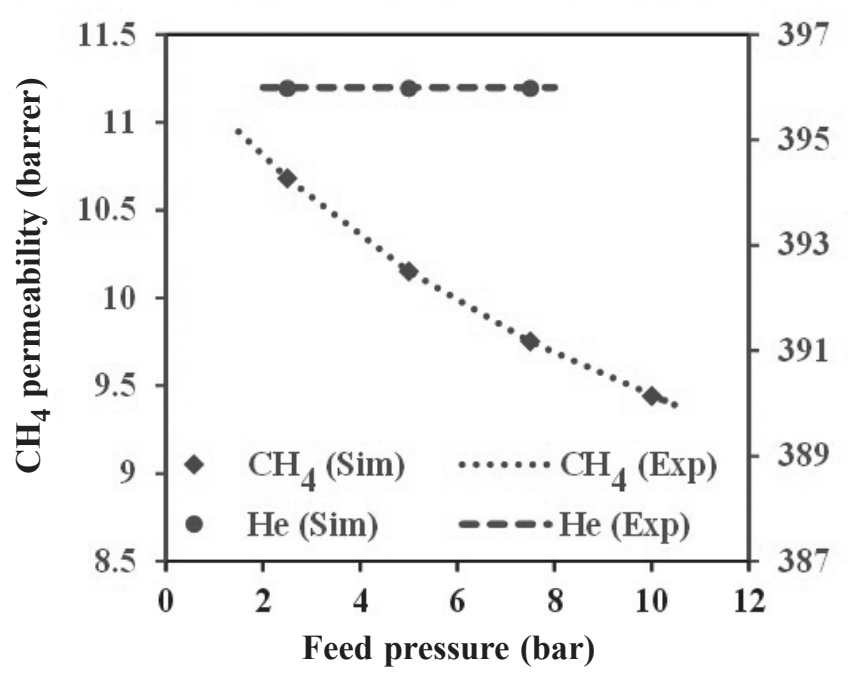

Fig. 4 - Validation of simulation data to experimental data $\left(\mathrm{CH}_{4}\right.$ data $^{62}$ and $\left.\mathrm{He}_{\text {data }}{ }^{66}\right)$

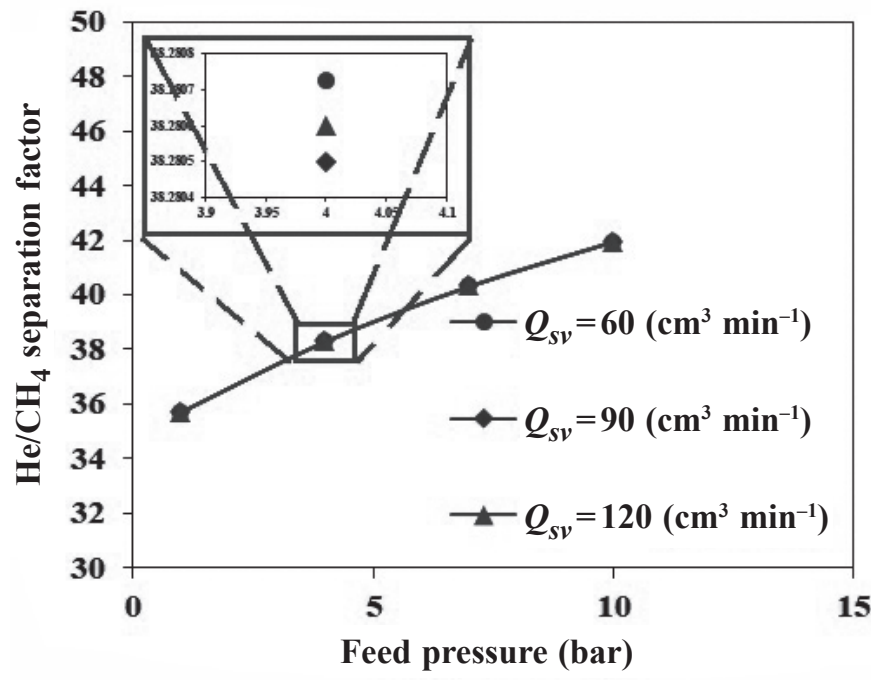

Fig. 5 - Impact of feed pressure on $\mathrm{He} / \mathrm{CH}_{4}$ separation factor at a different feed flow rate

mole fraction of gas components on both sides of the membrane ( $y$ and $x$ are mole fraction in permeate and feed side of the membrane, respectively). As the studied gas mixture was composed of two gases, calculating the mole fraction of one of the gases facilitated calculation of the other gas. Therefore, if the mole fraction of helium is determined, the separation factor can be calculated as follows:

$$
\alpha_{\mathrm{He} / \mathrm{CH}_{4}}=\frac{\frac{y_{\mathrm{He}}}{1-y_{\mathrm{He}}}}{\frac{x_{\mathrm{He}}}{1-x_{\mathrm{He}}}}
$$

In this section, the separation factor was calculated for different feed pressures and feed flow rates, as shown in Fig. 5. According to obtained results, the rising pressure value directly increased the separation factor, while the increase in feed flow rate had no effect on the amount of the separation factor. This indicated that the pressure must be increased to achieve a higher separation factor, and that there was no meaningful relationship between feed flow rate and separation factor.

\section{Effect of pressure and feed flow rate on $\mathrm{CH}_{4}$ and He flux}

The other important parameter, which is used in assessing membrane performance, is the gases membrane flux. Desired gas flux (helium) is high in the efficient membrane, while undesired gas flux (methane) is low. Thus, the impact of process parameters such as pressure and feed flow rate on helium and methane flux was examined. As shown in Fig. 6, methane flux strongly relied on the pressure, while there was no considerable dependence between methane flux and feed flow rate. According to Fig. 7, helium flux was highly proportional to feed pressure (like methane flux), while feed flow rate impacted helium flux, and increasing feed flow rate should also increase helium flux. As shown in the plots, the effectiveness of helium flux from pressure was higher than that of helium flux from the feed flow rate. These explanations show that it is better to increase pressure in order to gain more helium flux.

Results clearly show that both methane and helium membrane flux are functions of pressure. The concentration driving force is needed to penetrate gas components into the membrane, and the concentration driving force is profoundly affected by the partial pressure of gas components on the membrane surface (feed side). On the other hand, the partial pressure is directly proportional to feed pressure and gas component mole fraction. Therefore, flux is a function of (total) feed pressure.

Our results show that the variation of mole fraction of gases on the membrane surface due to changes in feed flow rate is the other reason for flux changes. According to the average mole fraction of helium on the membrane surface, it will be apparent that the average helium mole fraction increases about $7 \%$ when the feed flow rate rises from 60 to $120 \mathrm{~cm}^{3} \mathrm{~min}^{-1}$, and this difference leads to increase in helium flux. For methane flux, this variation is about $0.002 \%$. According to Fig. 6 , there is no significant change in methane flux when the feed flow rate is increased. It can be concluded that a change in feed flow rate can affect the gas membrane flux when it could cause a considerable change in gas mole fraction. Thus, high helium flux will be obtained when pressure and feed flow rate are high. In addition, the variation of feed flow rate has a considerable effect on helium flux, while it has no effect on methane flux practically. Therefore, it is reasonable to raise the feed flow rate as much as possible. 


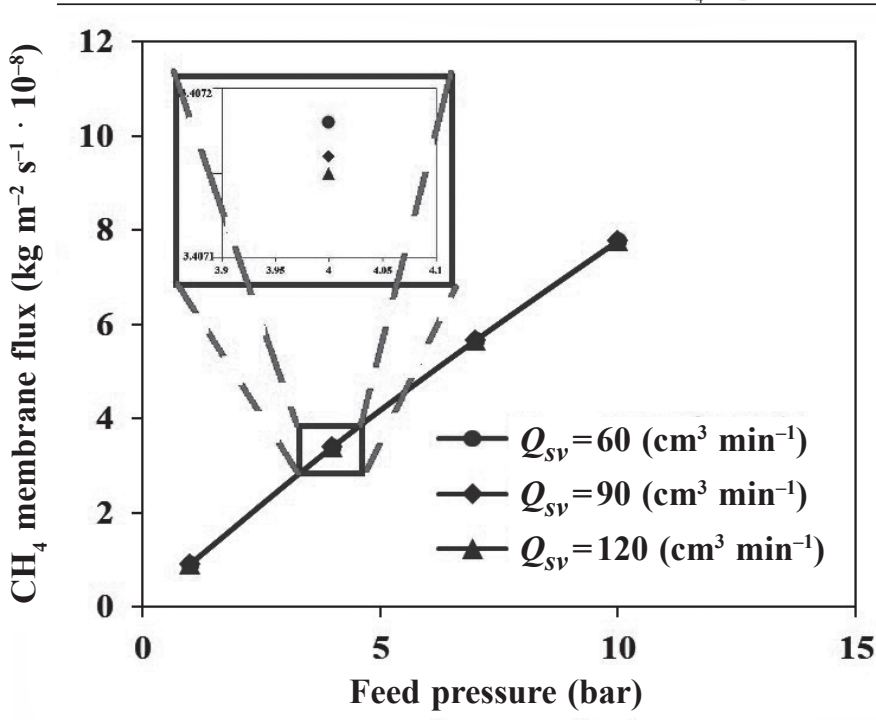

Fig. 6 - Impact of feed pressure on $\mathrm{CH}_{4}$ membrane flux at a different feed flow rate

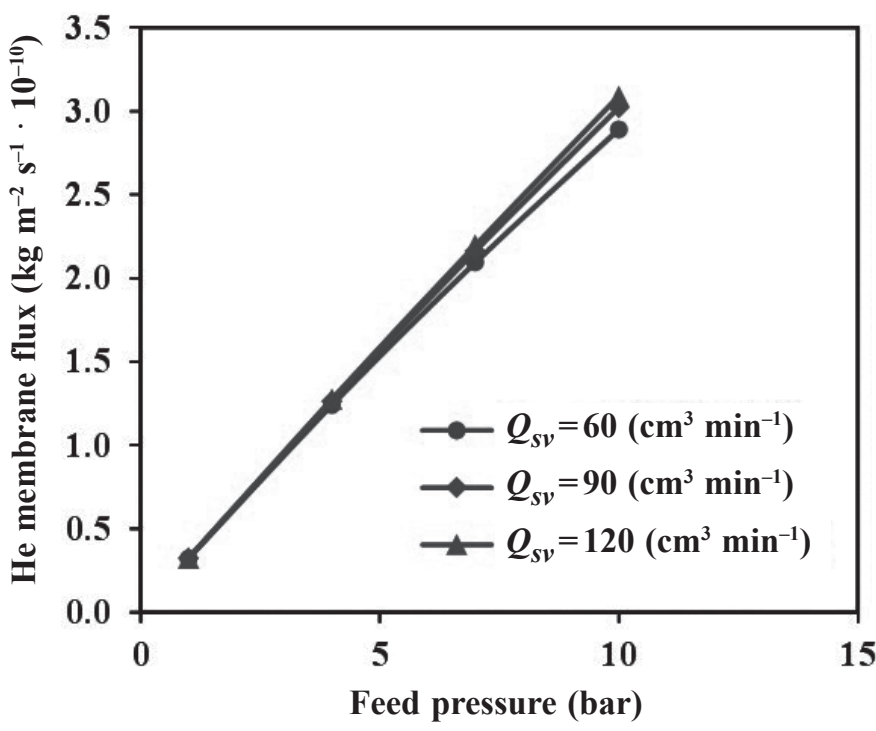

Fig. 7 - Impact of feed pressure on He membrane flux at a different feed flow rate

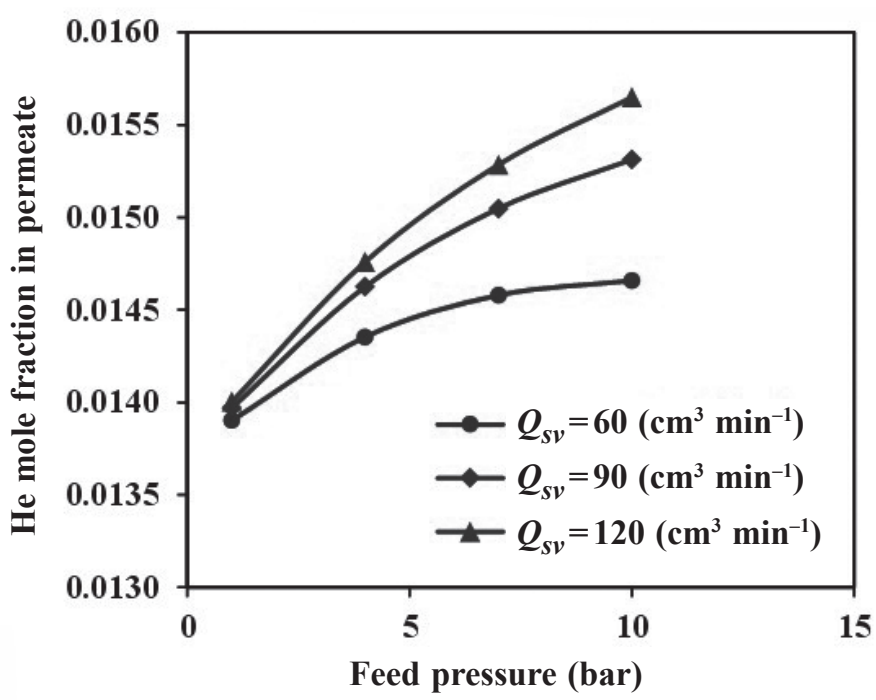

Fig. 8 - Impact of feed pressure on He mole fraction in permeate stream at a different feed flow rate

\section{Effect of feed pressure and feed flow rate on the permeate mole fraction}

In this section, helium mole fraction in the permeate stream for different pressures and feed flow rates were determined utilizing simulation, and the obtained results are presented in Fig. 8. According to this figure, the amount of helium mole fraction in permeate stream is added with the increase of pressure or feed flow rate. Also, the rate of this increase will be more and more when the amount of feed flow rate increases.

Indeed, helium mole fraction in the permeate stream is calculated from the ratio of helium membrane flux to the total membrane flux of methane and helium. As mentioned, the growth of feed flow rate will lead to a tangible increase in helium flux, but the variation of methane flux is not significant. Therefore, the amount of helium mole fraction in permeate stream is increased with the growth of feed flow rate. We can conclude that a feed pressure of 10 bar with a flow rate of $120 \mathrm{~cm}^{3} \mathrm{~min}^{-1}$ is the most efficient condition. This condition represents the maximum mole fraction of helium in permeate stream (according to Fig. 8).

\section{Effect of feed mole fraction on membrane flux}

Since the amount of helium concentration in different gas fields varies, tour aim was to evaluate the impact of helium concentration of feed stream on the performance of the membrane process. In this research, feeds with the helium mole fraction of 0.0004 (Iran, South Pars Gas Field) ${ }^{67}, 0.0021$ (Australia, Northern Territory, Palm Valley), 0.0053 (Canada, Alberta, Worsley), and 0.0254 (United States, Alaska, North Slope, South Barroweast $)^{68}$ were examined. Note that the other fraction of the feed will be considered methane, and the amounts of pressure and feed flow rate will be 10 bar and $120 \mathrm{~cm}^{3} \mathrm{~min}^{-1}$, respectively.

Fig. 9 and Fig. 10 illustrate the diagram of methane and helium membrane flux versus helium mole fraction in the feed stream, respectively.

According to Fig. 9, with the increase in helium mole fraction in the feed stream, the amount of methane flux reduced, which was, of course, a desirable result. The reason for this decrease in methane flux is that the amount of methane mole fraction in the feed stream had reduced as helium mole fraction increased. This will decrease methane partial pressure. Decreasing the partial pressure of methane in the feed stream reduces the concentration driving force, and this decreases methane membrane flux. On the other side, according to Fig. 10, with the increase in helium mole fraction in feed, the helium flux rises linearly. Indeed, the increase in helium mole fraction rises concentration driving force as well as helium membrane flux, linearly. 


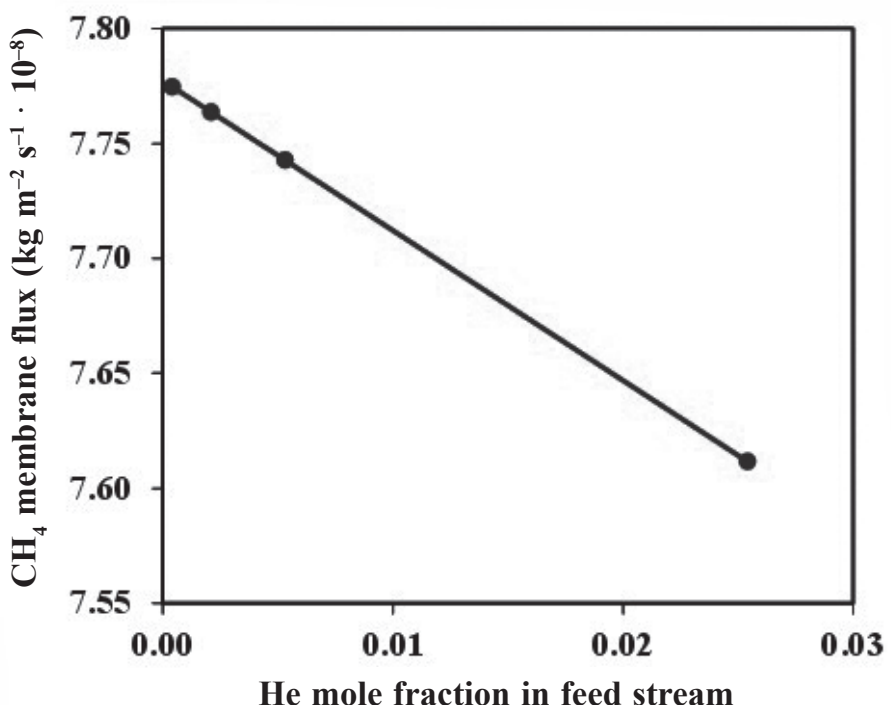

Fig. 9 - Impact of He mole fraction in feed stream on $\mathrm{CH}_{4}$ membrane flux

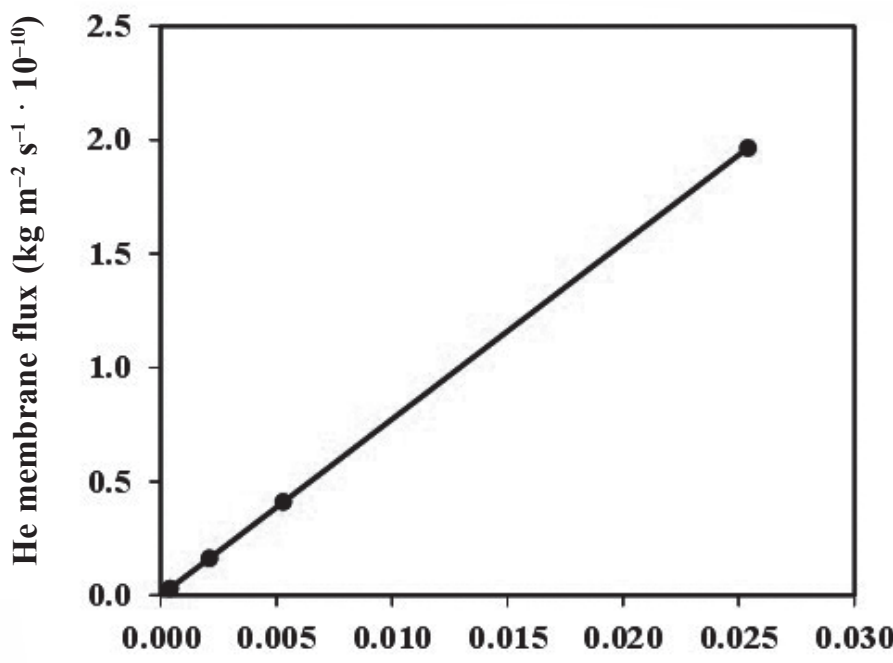

He mole fraction in feed stream

Fig. 10 - Impact of He mole fraction in feed stream on He membrane flux

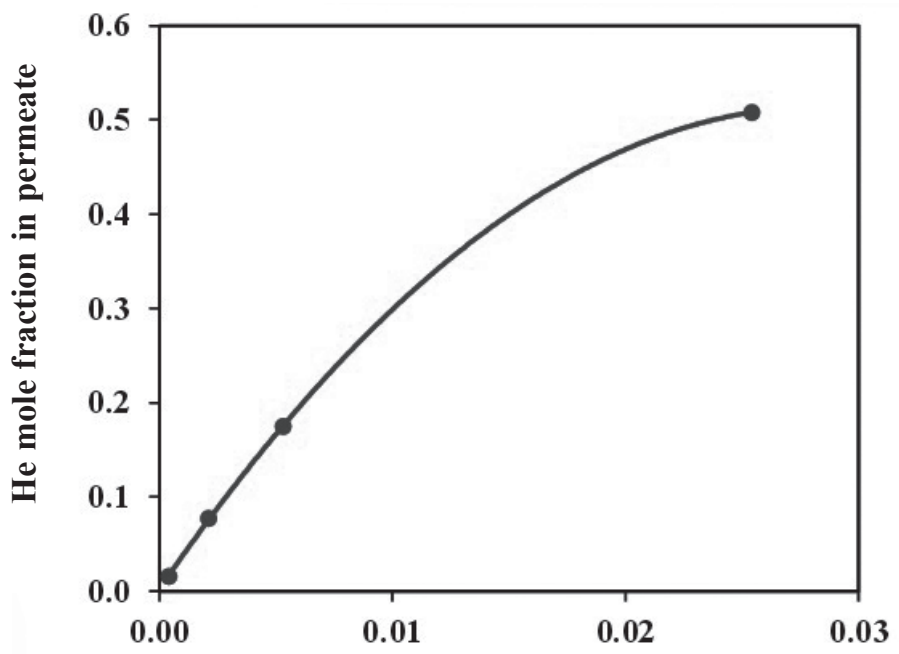

He mole fraction in feed stream

Fig. 11 - Impact of He mole fraction in feed stream on He mole fraction in permeate
Effect of helium mole fraction in feed stream on helium mole fraction in the permeate stream

In Fig. 11, the impact of helium mole fraction of feed stream on helium mole fraction in permeate stream is illustrated. According to this figure, the amount of helium mole fraction in the permeate stream is increased from 0.0156 to 0.5081 , with the rise of helium mole fraction in the feed stream from 0.0004 to 0.0254 . In other words, the amount of helium mole fraction in permeate stream increased about 33 times when helium mole fraction in feed stream increased about 64 times. Therefore, a slight increase in helium mole fraction in the feed stream improves the performance of the membrane separation process. According to Fig. 11, the increasing procedure of helium mole fraction in the feed stream is not linear. As shown in Eq. 41, the relationship between $\mathrm{He} / \mathrm{CH}_{4}$ membrane flux $\left(\frac{N_{\mathrm{He}}}{N_{\mathrm{CH}_{4}}}\right)$ and helium mole fraction in permeate stream $\left(y_{\mathrm{He}}\right)$ is nonlinear. As shown in the previous part, the amount of helium flux $\left(N_{\mathrm{He}}\right)$ increased with the rise of helium mole fraction in feed stream while the amount of methane flux $\left(N_{\mathrm{CH}}\right)$ decreased. Therefore, the nonlinear relationship between helium mole fraction in the feed stream and helium mole fraction in permeate stream will be confirmed in theoretical analyses.

$$
y_{\mathrm{He}}=\frac{N_{\mathrm{He}}}{N_{\mathrm{He}}+N_{\mathrm{CH}_{4}}}=\frac{1}{1+\frac{1}{\frac{N_{\mathrm{He}}}{N_{\mathrm{CH}_{4}}}}}
$$

\section{Conclusion}

In this study, the impact of feed flow rate and feed pressure on $\mathrm{He} / \mathrm{CH}_{4}$ separation factor for a feed with the helium mole fraction of 0.0004 was initially studied. The results revealed that rising pressure increased the separation factor, but the feed flow rate had no impact on the separation factor. In the present work, the effects of feed flow rate and pressure on the membrane flux of methane and helium were examined comprehensively. According to the results of simulations, methane flux strongly relied on the pressure but there was no significant functionality between feed flow rate and methane membrane flux. Our findings show that it is better to increase pressure to obtain higher helium flux. Mole fraction of permeate stream is another crucial parameter that was used in analyzing membrane process performance. Our results confirm that increasing either feed pressure or feed flow rate will rise helium mole fraction in the permeate stream. Our findings demonstrate that the pressure of $10 \mathrm{bar}$ 
with $120 \mathrm{~cm}^{3} \mathrm{~min}^{-1}$ feed flow rate is an efficient condition since the amounts of separation factor, helium flux, and helium mole fraction in permeate stream were maximum in this condition.

Additionally, the impact of helium mole fraction in feed stream on methane and helium membrane flux and helium mole fraction in permeate stream was examined in the optimum condition. The results indicated that the amount of methane flux decreased with the increase in helium mole fraction in the feed stream, while the amount of helium flux increased. Moreover, the amounts of helium mole fraction in permeate stream increased from 0.0156 to 0.5081 nonlinearly with the increase in helium mole fraction in feed stream from 0.0004 to 0.0254 . Thus, the increase in helium concentration in the feed stream improved the performance of the Hyflon AD60X membrane.

\section{Nomenclature}

\section{Symbols}

A Stiff-Spring velocity, $\mathrm{m} \mathrm{s}^{-1}$

Constant for calculation of collision integral

Constant for calculation of collision integral

$b \quad$ Langmuir affinity constant, $\mathrm{atm}^{-1}$

C Constant for calculation of collision integral

$C_{H}^{*} \quad$ Langmuir capacity constant, $\mathrm{cm}^{3}[\mathrm{STP}] \mathrm{cm}^{-3}$ [polymer]

c Concentration, $\mathrm{mol} \mathrm{m}^{-3}$

$D \quad$ Diffusion coefficient, $\mathrm{m}^{2} \mathrm{~s}^{-1}$

d driving force

E Constant for calculation of collision integral

$F \quad$ Moving fraction of Langmuir's population, Constant for calculation of collision integral

$G \quad$ Constant for calculation of collision integral

$H$ Constant for calculation of collision integral

I Identity tensor

$j \quad$ Mass flux (diffusion), $\mathrm{kg} \mathrm{m}^{-2} \mathrm{~s}^{-1}$

$K \quad$ Partition coefficient

$K_{D} \quad$ Henry's law constant, $\mathrm{cm}^{3}[\mathrm{STP}] \mathrm{cm}^{-3}[$ polymer $] \mathrm{atm}^{-1}$

$M \quad$ Molecular weight, $\mathrm{g} \mathrm{mol}^{-1}$

$N \quad$ Mass flux, $\mathrm{kg} \mathrm{m}^{-2} \mathrm{~s}^{-1}$

$N^{*} \quad$ Molar flux, mol m $\mathrm{m}^{-2} \mathrm{~s}^{-1}$

$n \quad$ Normal vector

$p \quad$ Pressure, $\mathrm{Pa}$

$Q_{s v} \quad$ Volumetric flow rate at standard condition, $\mathrm{m}^{3} \mathrm{~s}^{-1}$

$R \quad$ Production rate, $\mathrm{kg} \mathrm{m}^{-3} \mathrm{~s}^{-1}$

$r \quad$ Radial coordinate, $\mathrm{m}$

$T$ Temperature, $\mathrm{K}$

$T^{*} \quad$ Dimensionless temperature $u \quad$ Velocity vector, $\mathrm{m} \mathrm{s}^{-1}$

$x \quad$ Mole fraction

$y \quad$ Mole fraction

$z \quad$ Axial coordinate, $\mathrm{m}$

\section{Greek letters}

$\alpha \quad$ Separation factor

$\varepsilon \quad$ Characteristic energy of interaction between molecules, ergs

$k \quad$ Boltzmann constant, ergs $\mathrm{K}^{-1}$

$\mu \quad$ Fluid viscosity, $\mathrm{Pa} \mathrm{s}$

$\rho \quad$ Fluid density, $\mathrm{kg} \mathrm{m}^{-3}$

$\sigma \quad$ Collision diameter, $\AA$

$\Omega_{D} \quad$ Collision integral for molecular diffusion calculation

$\Omega_{\mu} \quad$ Collision integral for viscosity calculation

$\omega \quad$ Mass fraction

\section{Subscripts}

A Absolute

$i \quad$ Species

j Species

$\mathrm{k} \quad$ Species

st Standard

$\mathrm{t}$ Total

\section{References}

1. Sunarso, J., Hashim, S. S., Lin, Y., Liu, S., Membranes for helium recovery: An overview on the context, materials and future directions, Sep. and Puri. Technol. 176 (2017) 335. doi: https://doi.org/10.1016/j.seppur.2016.12.020

2. Glowacki, B. A., Nuttall, W. J., Clarke, R. H., Beyond the helium conundrum, IEEE transactions on Appl. Superconductivity 23 (2013) 0500113. doi: https://doi.org/10.1109/TASC.2013.2244633

3. Mohr, S., Ward, J., Helium production and possible projection, Minerals 4 (2014) 130. doi: https://doi.org/10.3390/min4010130

4. Bradshaw, A. M., Hamacher, T., Nuclear fusion and the helium supply problem, Fusion Eng. and Des. 88 (2013) 2694.

doi: https://doi.org/10.1016/j.fusengdes.2013.01.059

5. Nuttall, W. J., Clarke, R. H., Glowacki, B. A., Stop squandering helium, Nature 485 (2012) 573. doi: https://doi.org/10.1038/485573a

6. Koosha, N., Karimi-Sabet, J., Moosavian, M. A., Amini, Y., Improvement of synthesized graphene structure through various solvent liquids at low temperatures by chemical vapor deposition method, Mat. Sci. and Eng.: B 274 (2021) 115458. doi: https://doi.org/10.1016/j.mseb.2021.115458

7. Scholes, C. A., Gosh, U. K., Ho, M. T., The economics of helium separation and purification by gas separation membranes, Ind. \& Eng. Chem. Res. 56 (2017) 5014. doi: https://doi.org/10.1021/acs.iecr.7b00976 
8. Ahmadi-Motlagh, M., Amini, Y., Karimi-Sabet, J., Experimental study of nitrogen isotope separation by ion-exchange chromatography: Effect of process factors, J. of Radioanalytical and Nuc. Chem. (2021) 1 . doi: https://doi.org/10.1007/s10967-021-08079-y

9. Sridhar, S., Smitha, B., Aminabhavi, T., Separation of carbon dioxide from natural gas mixtures through polymeric membranes - a review, Sep. \& Pur. Rev. 36 (2007) 113 doi: https://doi.org/10.1080/15422110601165967

10. Marsousi, S., Karimi-Sabet, J., Moosavian, M. A., Amini, $Y$., Liquid-liquid extraction of calcium using ionic liquids in spiral microfluidics, Chem. Eng. J. 356 (2019) 492. doi: https://doi.org/10.1016/j.cej.2018.09.030

11. Jahromi, P. F., Karimi-Sabet, J., Amini, Y., Ion-pair extraction-reaction of calcium using Y-shaped microfluidic junctions: An optimized separation approach, Chem. Eng. J. 334 (2018) 2603. doi: https://doi.org/10.1016/j.cej.2017.11.129

12. Dastbaz, A., Karimi-Sabet, J., Ahadi, H., Amini, Y., Preparation and characterization of novel modified PVDF-HFP/ GO/ODS composite hollow fiber membrane for Caspian Sea water desalination, Desalination 424 (2017) 62 doi: https://doi.org/10.1016/j.desal.2017.09.030

13. Moradi, R., Karimi-Sabet, J., Shariaty-Niassar, M., Amini, $Y$., Air gap membrane distillation for enrichment of $\mathrm{H} 218 \mathrm{O}$ isotopomers in natural water using poly (vinylidene fluoride) nanofibrous membrane, Chem. Eng. and Processing: Proc. Intens. 100 (2016) 26. doi: https://doi.org/10.1016/j.cep.2015.11.015

14. Moradi, R., Monfared, S. M., Amini, Y., Dastbaz, A., Vacuum enhanced membrane distillation for trace contaminant removal of heavy metals from water by electrospun PVDF/ $\mathrm{TiO}_{2}$ hybrid membranes, Korean J. of Chem. Eng. 33 (2016) 2160. doi: https://doi.org/10.1007/s11814-016-0081-y

15. Moradi, R., Karimi-Sabet, J., Shariaty-niassar, M., Amini, $Y$, Experimental investigation of nanofibrous poly (vinylidene fluoride) membranes for desalination through air gap membrane distillation process, Korean J. of Chem. Eng. 33 (2016) 2953. doi: https://doi.org/10.1007/s11814-016-0081-y

16. Iarikov, D. D., Oyama, S. T., Review of $\mathrm{CO}_{2} / \mathrm{CH}_{4}$ separation membranes, Membrane Sci. and Technol. 14 (2011) 91. doi: https://doi.org/10.1016/B978-0-444-53728-7.00005-7

17. Bakonyi, P., Nemestóthy, N., Bélafi-Bakó, K., Biohydrogen purification by membranes: An overview on the operational conditions affecting the performance of non-porous, polymeric and ionic liquid based gas separation membranes, Inter. J. of Hyd. Energy 38 (2013) 9673. doi: https://doi.org/10.1016/j.ijhydene.2013.05.158

18. Jansen, J. C., Macchione, M., Drioli, E., On the unusual solvent retention and the effect on the gas transport in perfluorinated Hyflon $\mathrm{AD} \AA$ membranes, J. of Membrane Sci. 287 (2007) 132 doi: https://doi.org/10.1016/j.ijhydene.2013.05.158

19. Robeson, L. M., The upper bound revisited, J. of Membrane Sci. 320 (2008) 390. doi: https://doi.org/10.1016/j.memsci.2008.04.030

20. Moradi, R., Mahyari, A., Gerdroodbary, M. B., Abdollahi, A., Amini, Y., Shape effect of cavity flameholder on mixing zone of hydrogen jet at supersonic flow, Inter. J. of Hyd. Energy 43 (2018) 16364.

doi: https://doi.org/10.1016/j.ijhydene.2018.06.166

21. Moradi, R., Mosavat, M., Gerdroodbary, M. B., Abdollahi, A., Amini, $Y$., The influence of coolant jet direction on heat reduction on the nose cone with Aerodome at supersonic flow, Acta Astronautica 151 (2018) 487. doi: https://doi.org/10.1016/j.actaastro.2018.06.026
22. Hassanvand, A., Gerdroodbary, M. B., Moradi, R., Amini, $Y$., Application of Knudsen thermal force for detection of inert gases, Results in Phy. 9 (2018) 351. doi: https://doi.org/10.1016/j.rinp.2018.02.002

23. Hashemipour, N., Karimi-Sabet, J., Motahari, K., Monfared, S. M., Amini, Y., Moosavian, M. A., Experimental and simulation investigation on separation of binary hydrocarbon mixture by thermogravitational column, J. of Mol. Liq. 268 (2018) 791. doi: https://doi.org/10.1515/cppm-2021-0036

24. Anazadehsayed, A., Gerdroodbary, M. B., Amini, Y. Moradi, R., Mixing augmentation of transverse hydrogen jet by injection of micro air jets in supersonic crossflow, Acta Astronautica 137 (2017) 403. doi: https://doi.org/10.1016/j.actaastro.2017.05.007

25. Gerdroodbary, M. B., Amini, Y., Ganji, D., Takam, M. R., The flow feature of transverse hydrogen jet in presence of micro air jets in supersonic flow, Adv. in Space Res. 59 (2017) 1330. doi: https://doi.org/10.1016/j.asr.2016.11.040

26. Karbasi, E., Karimi-Sabet, J., Mohammadi-Rovshandeh, J., Moosavian, M. A., Ahadi, H., Amini, Y., Experimental and numerical study of air-gap membrane distillation (AGMD): Novel AGMD module for Oxygen-18 stable isotope enrichment, Chem. Eng. J. 322 (2017) 667. doi: https://doi.org/10.1016/j.cej.2017.03.031

27. Jahromi, P. F., Karimi-Sabet, J., Amini, Y., Fadaei, H., Pressure-driven liquid-liquid separation in Y-shaped microfluidic junctions, Chem. Eng. J. 328 (2017) 1075. doi: https://doi.org/10.1016/J.CEJ.2017.07.096

28. Amini, Y., Karimi-Sabet, J., Nasr Esfahany, M., Experimental characterization of new wire gauze with high capacity structured packing, The Canadian J. of Chem. Eng. 95 (2017) 535 . doi: https://doi.org/10.1002/cjce.22731

29. Amini, Y., Karimi-Sabet, J., Esfahany, M. N., Characterization of new wire gauze high-capacity structured packing with varied inclination angle, Chem. Eng. \& Technol. 40 (2017) 581 . doi: https://doi.org/10.1002/ceat.201600351

30. Amini, Y., Karimi-Sabet, J., Esfahany, M. N., Experimental and numerical simulation of dry pressure drop in high-capacity structured packings, Chem. Eng. \& Technol. 39 (2016) 1161. doi: https://doi.org/10.1002/ceat.201500477

31. Sadeghi, A., Amini, Y., Saidi, M. H., Yavari, H., Shear-rate-dependent rheology effects on mass transport and surface reactions in biomicrofluidic devices, AIChE J. 61 (2015) 1912. doi: https://doi.org/10.1002/aic.14781

32. Sadeghi, A., Amini, Y., Saidi, M. H., Chakraborty, S., Numerical modeling of surface reaction kinetics in electrokinetically actuated microfluidic devices, Analy. Chim. Acta 838 (2014) 64. doi: https://doi.org/10.1016/j.aca.2014.05.023

33. Esmaeili Faraj, S. H., Nasr Esfahany, M., Amini, Y., Modeling of biofiltration process for removal of vinyl chloride from an air stream by modified ottengraf model, J. of Petr. Res. 24 (2014) 21. doi: https://doi.org/10.22078/PR.2014.405

34. Amini, Y., Gerdroodbary, M. B., Pishvaie, M. R., Moradi, R., Monfared, S. M., Optimal control of batch cooling crystallizers by using genetic algorithm, Case Stud. in Thermal Eng. 8 (2016) 300. doi: https://doi.org/10.1016/j.csite.2016.09.001 
35. Amini, Y., Mokhtari, M., Haghshenasfard, M., Gerdroodbary, M. B., Heat transfer of swirling impinging jets ejected from Nozzles with twisted tapes utilizing CFD technique, Case Stud. in Thermal Eng. 6 (2015) 104.

doi: https://doi.org/10.1016/j.csite.2015.08.001

36. Amini, Y., Fattahi, M., Khorasheh, F., Sahebdelfar, S., Neural network modeling the effect of oxygenate additives on the performance of $\mathrm{Pt}-\mathrm{Sn} / \gamma-\mathrm{Al}_{2} \mathrm{O}_{3}$ catalyst in propane dehydrogenation, Appl. Petro. Res. 3 (2013) 47. doi: https://doi.org/10.1007/s13203-013-0028-8

37. Laguntsov, N., Kurchatov, I., Karaseva, M., Solomahin, V., On the use of membrane technology for helium extraction from high-pressure natural gas, Petro. Chem. 54 (2014) 673. doi: https://doi.org/10.1134/S0965544114080088

38. Perrin, J., Stern, S., Separation of a helium-methane mixture in permeators with two types of polymer membranes, AIChE J. 32 (1986) 1889. doi: https://doi.org/10.3390/pr8050560

39. Ahsan, M., Hussain, A., Mathematical modeling of helium recovery from a multicomponent fuel gas with polymeric membrane, Inter. J. of Chem. Eng. and Appl. 6 (2015) 173. doi: https://doi.org/10.7763/IJCEA.2015.V6.476

40. Naumkin, V., Simulation of helium-methane mixture separation on selectively permeable membranes, Journal of Phy.: Conference Series, IOP Publishing, 2016, p. 022007. doi: https://doi.org/10.1088/1742-6596/754/2/022007

41. Volchkov, E., Dvornikov, N., Naumkin, V., Simulation of the separation of a helium-methane mixture in a flat membrane module, Theoretical Foundations of Chem. Eng. 50 (2016) 343.

doi: https://doi.org/10.1134/S0040579516030143

42. Tang, W., Wan, S., Yang, Z., Teschendorff, A. E., Zou, Q., Tumor origin detection with tissue-specific miRNA and DNA methylation markers, Bioinformatics 34 (2018) 398. doi: https://doi.org/10.1093/bioinformatics/btx622

43. $W u, H$., Zhang, F., Zhang, Z., Droplet breakup and coalescence of an internal-mixing twin-fluid spray, Phy. of Fluids 33 (2021) 013317. doi: https://doi.org/10.1063/5.0030777

44. Shi, M., Wang, F., Lan, P., Zhang, Y., Zhang, M., Yan, Y., Liu, $Y$., Effect of ultrasonic intensity on structure and properties of wheat starch-monoglyceride complex and its influence on quality of norther-style Chinese steamed bread, Food Sci. \& Technol. 138 (2021) 110677. doi: https://doi.org/10.1016/j.lwt.2020.110677

45. Shi, M., Wang, F., Lan, P., Zhang, Y., Zhang, M., Yan, Y., $\mathrm{Liu}, Y$., Effect of ultrasonic intensity on structure and properties of wheat starch-monoglyceride complex and its influence on quality of norther-style Chinese steamed bread, LWT 138 (2021) 110677. doi: https://doi.org/10.1016/j.lwt.2020.110677

46. Hassanvand, A., Saei Moghaddam, M., Barzegar Gerdroodbary, M., Amini, Y., Analytical study of heat and mass transfer in axisymmetric unsteady flow by ADM, Journal of Comp. \& Appl. Res. in Mech. Eng. (JCARME) 11 (2021) 151 . doi: https://doi.org/10.22061/JCARME.2019.3456.1399

47. Salimi, H., Hashemipour, N., Karimi-Sabet, J., Amini, Y., Appling the computational fluid dynamics studies of the thermogravitational column for $\mathrm{N}_{2}-\mathrm{CO}_{2}$ and $\mathrm{He}-\mathrm{Ar}$ gas mixtures separation, Chem. Prod. and Pro. Mod. (2021). doi: https://doi.org/10.1515/cppm-2021-0036

48. Edalatpour, A., Hassanvand, A., Gerdroodbary, M. B., Moradi, R., Amini, Y., Injection of multi hydrogen jets within cavity flameholder at supersonic flow, Inter. J. of Hyd. Energy 44 (2019) 13923. doi: https://doi.org/10.1016/J.IJHYDENE.2019.03.117

49. Amini, Y., Nasr Esfahany, M., CFD simulation of the structured packings: A review, Sep. Sci. and Technol. 54 (2019) 2536. doi: https://doi.org/10.1080/01496395.2018.1549078

50. Hashemipour, N., Karimi-Sabet, J., Motahari, K., Monfared, S. M., Amini, Y., Moosavian, M. A., Numerical study of n-heptane/benzene separation by thermal diffusion column, Chinese J. of Chem. Eng. 27 (2019) 1745. doi: https://doi.org/10.1016/j.cjche.2018.10.004

51. Amini, Y., Karimi-Sabet, J., Nasr Esfahany, M., Haghshenasfard, M., Dastbaz, A., Experimental and numerical study of mass transfer efficiency in new wire gauze with high capacity structured packing, Sep. Sci. and Technol. 54 (2019) 2706 . doi: https://doi.org/10.1080/01496395.2018.1549076

52. Coroneo, M., Montante, G., Catalano, J., Paglianti, A., Modelling the effect of operating conditions on hydrodynamics and mass transfer in a $\mathrm{Pd}-\mathrm{Ag}$ membrane module for $\mathrm{H}_{2}$ purification, J. of Membrane Sci. 343 (2009) 34. doi: https://doi.org/10.1016/j.memsci.2009.07.008

53. Zhang, C., Liu, X., Liu, C., Luo, X., Characterization of the Complete Mitochondrial Genome of Acanthacorydalis fruhstorferi van der Weele (Megaloptera: Corydalidae), J. of the Kansas Entomological Soc. 93 (2021) 267. doi: https://doi.org/10.2317/0022-8567-93.4.267

54. Amini, Y., Shadman, M. M., Karimi-Sabet, J., CFD simulation of flow distribution in the randomly packed bed Dixon ring, Sep. Sci. and Technol. (2021) 1. doi: https://doi.org/10.1080/01496395.2021.2009513

55. Sanders, D. F., Smith, Z. P., Guo, R., Robeson, L. M., McGrath, J. E., Paul, D. R., Freeman, B. D., Energy-efficient polymeric gas separation membranes for a sustainable future: A review, Polymer 54 (2013) 4729. doi: https://doi.org/ 10.1016/j.polymer.2013.05.075

56. Lau, C. H., Li, P., Li, F., Chung, T. S., Paul, D. R., Reverse-selective polymeric membranes for gas separations, Prog. in Polymer Sci. 38 (2013) 740. doi: https://doi.org/10.1016/j.progpolymsci.2012.09.006

57. Freeman, B., Yampolskii, Y., Pinnau, I., Materials science of membranes for gas and vapor separation, John Wiley \& Sons, 2006. doi: https://doi.org/10.1002/047002903X

58. Sun, J., Du, H., Chen, Z., Wang, L., Shen, G., MXene quantum dot within natural 3D watermelon peel matrix for biocompatible flexible sensing platform, Nano Res. (2021). doi: https://doi.org/10.1007/s12274-021-3967-x

59. Abdollahi, P., Karimi-Sabet, J., Moosavian, M. A., Amini, $Y$, Microfluidic solvent extraction of calcium: Modeling and optimization of the process variables, Sep. and Pur. Technol. 231 (2020) 115875. doi: https://doi.org/10.1016/j.seppur.2019.115875

60. Shehni, P. M., Amooghin, A. E., Ghadimi, A., Sadrzadeh, M., Mohammadi, T., Modeling of unsteady-state permeation of gas mixture through a self-synthesized PDMS membranes, Sep. and Pur. Technol. 76 (2011) 385. doi: https://doi.org/10.1016/j.jiec.2012.11.003

61. Smith, Z. P., Tiwari, R. R., Dose, M. E., Gleason, K. L., Murphy, T. M., Sanders, D. F., Gunawan, G., Robeson, L. M., Paul, D. R., Freeman, B. D., Influence of diffusivity and sorption on helium and hydrogen separations in hydrocarbon, silicon, and fluorocarbon-based polymers, Macromolecules 47 (2014) 3170. doi: https://doi.org/10.1021/ma402521h 
62. Scholes, C. A., Kanehashi, S., Stevens, G. W., Kentish, S. E. Water permeability and competitive permeation with $\mathrm{CO}$ and $\mathrm{CH}_{4}$ in perfluorinated polymeric membranes, Sep. and Pur. Technol. 147 (2015) 203.

doi: https://doi.org/10.1016/j.seppur.2015.04.023

63. Poling, B. E., Prausnitz, J. M., O'connell, J. P., Properties of gases and liquids, McGraw-Hill Education 2001. doi: https://doi.org/10.1036/0070116822

64. Amini, Y., Karimi-Sabet, J., Esfahany, M. N., Experimental and numerical study of multiphase flow in new wire gauze with high capacity structured packing, Chem. Eng. and Proc.: Proc. Intens. 108 (2016) 35. doi: https://doi.org/10.1080/01496395.2018.1549076

65. Gerdroodbary, M. B., Ganji, D., Amini, Y., Numerical study of shock wave interaction on transverse jets through multi- port injector arrays in supersonic crossflow, Acta Astronautica 115 (2015) 422.

doi: https://doi.org/10.1016/j.actaastro.2015.06.002

66. Branken, D., Krieg, H., Le Roux, J., Lachmann, G., Separation of NF3 and CF4 using amorphous glassy perfluoropolymer Teflon AF and Hyflon AD60 membranes, J. of Membrane Sci. 462 (2014) 75

doi: https://doi.org/10.1016/j.memsci.2014.03.033

67. Heidari, M., Tavasoli, A., Karimi, A., multi-objective optimization of a combined cryogenic and membrane process for helium recovery from natural gas using genetic algorithm, Petroleum \& Coal 57 (2015).

68. Chadwick, S. S., Ullmann's encyclopedia of industrial chemistry, Reference Services Review (1988). doi: https://doi.org/ 10.1108/eb049034 